\title{
Analisis Perilaku Konsumen dalam Pembelian Daging Ayam Ras Pedaging Di Pasar Tradisional Amuntai
}

\author{
(Analysis of Consumer Behavior In Purchasing Broiler Chicken \\ in Amuntai Traditional Market)
}

\author{
Purna Kusumayana $^{1)}$ \& Selvia Seftiani ${ }^{2)}$ \\ Program Studi Agribisnis, Sekolah Tinggi Ilmu Pertanian Amuntai \\ ${ }^{1)}$ kusumayanapurna@yahoo.com \\ ${ }^{2)}$ selviani@gmail.com
}

\begin{abstract}
ABSTRAK
Penelitian ini bertujuan untuk mengidentifikasi karakteristik konsumen dan menganalisis faktorfaktor yang mempengaruhi perilaku konsumen dalam membeli daging ayam ras pedaging di pasar tradisional amuntai. Metode pengumpulan data dengan metode wawancara langsung kepada konsumen yang membeli daging ayam ras pedaging. Pengumpulan data dilakukan dengan metode accidental sampling siapa saja yang ditemui yaitu konsumen daging ayam ras pedaging, dengan responden sebanyak 75 orang. Berdasarkan hasil penelitian diketahui bahwa karakteristik konsumen yang mendominasi adalah jenis kelamin perempuan 64 orang (85,3\%), usia 41-50 tahun 33 orang (44\%), tingkat pendidikan SMA 34 orang (45,3\%), jenis pekerjaan sabagai ibu rumah tangga 28 orang (37,3\%), dengan pendapatan Rp. 1.000.000 - Rp. 2.000.000 25 orang 933,3\%). Hasil analisis regrasi diperoleh nilai koefisien determinasi $\left(R^{2}\right)$ sebesar0,458 atau 45,8\% terdapat pengaruh variabel independen meliputi budaya, sosial, pribadi, dan psikologis terhadap keputusan pembelian, sedangkan 54,2\% dipengaruhi oleh faktor lain yang tidak termasuk dalam model regresi tersebut. Dari hasil pengujian regrasi sebagai berikut: $Y=5,633+0,421$ $X_{1}-0,208 X_{2}+0,055 X_{3}+0,300 X_{4}$. Secara simultan variabel independen meliputi budaya, sosial, pribadi, dan psikologis berpengaruh signifikan terhadap keputusan pembelian. Secara parsial faktor budaya, sosial dan psikologis berpengaruh nyata terhadap keputusan pembelian sedangkan faktor pribadi tidak berpengaruh nyata terhadap keputusan pembelian.
\end{abstract}

Kata Kunci: Karakteristik, konsumen, daging, ayam, pembelian.

\section{ABSTRACT}

This study aimed to identify the characteristics of consumers and analyze the factors that influence consumer behavior in buying broiler meat in the traditional market Amuntai. Methods of data collection by direct interview method to consumers who buy broiler meat. Data collection was done by accidental sampling method who met the broiler meat consumers, with 75 respondents. Based on the result of research, it is known that the dominant consumer characteristic is female gender 64 people (85,3\%), age 41-50 years 33 people (44\%), high school education level 34 people (45,3\%), households 28 people (37.3\%), with income Rp. 1,000,000 - Rp. 2,000,000 25 people 933.3\%). Regression analysis results obtained value of coefficient of determination (R2) of 0, 458 or $45.8 \%$ there is the influence of independent variables include cultural, social, personal, and psychological to purchase decisions, while $54.2 \%$ influenced by other factors not included in the regression model From the results of regression testing as follows: $Y=5,633+0,421$ $X_{1}-0,208 X_{2}+0,055 X_{3}+0,300 X_{4}$. Simultaneously independent variables include cultural, social, personal, and psychological significant effect on purchasing decisions. Partially cultural, social and psychological factors significantly affect purchasing decisions while personal factors have no significant effect on purchasing decisions.

Keywords: Characteristics, consumers, meat, chicken, purchases.

\section{PENDAHULUAN}

Pertanian dalam arti luas, yaitu suatu bidang usaha yang mencakup bidang tanaman, bidang peternakan dan bidang perikanan. Pertanian dalam arti sempit yaitu suatu usaha hanya dibidang tanaman. Pertanian disini hanya mengutamakan budidaya tanaman, tidak dikemukakan faktor-faktor apa saja yang mendukung, 
terkait atau merupakan pengembangan dari kegiatan budidaya tersebut (Fatah, 2007).

Salah satu sektor pertanian diantaranya adalah sektor peternakan. Peternakan berperan penting dalam pemenuhan pangan hewani berupa daging, susu, dan telor. Usaha pengembangan peternakan saat ini menunjukkan prospek yang sangat cerah dan mempunyai peranan penting dalam pertumbuhan ekonomi pertanian. Sebagian besar masyarakat dunia mengakui bahwa produk-produk peternakan memegang peranan yang sangat penting di masa yang akan datang (Sosilorini, 2011).

Ayam merupakan unggas penghasil daging yang sangat populer di masyarakat Indonesia saat ini. Hal ini karena usaha peternakan ayam masih merupakan sektor kegiatan yang paling cepat dan paling efisien untuk memenuhi kebutuhan daging bagi masyarakat. Faktor penyebabnya antara lain permodalan yang relatif kecil, perputaran modal relatif lebih cepat, penggunaan lahan yang tidak terlalu luas, dan laju pertumbuhan yang lebih cepat dibandingkan dengan ternak lain (Nuroso, 2011).

Ayam yang dipelihara untuk dimanfaatkan dagingnya disebut ayam pedaging. Adapun ayam ras pedaging yang unggul dikenal dengan nama broiler. Ayam tersebut dihasilkan melalui perkawinan silang, seleksi, dan rekayasa genetik yang dilakukan oleh pembibitannya. Broiler merupakan jenis ras unggulan hasil persilangan dari bangsa-bangsa ayam yang memiliki produktivitas tinggi, terutama dalam memproduksi daging (Santoso dan Sudaryani, 2015).

Adapun tujuan penelitian ini adalah mengetahui (ii) karakteristik konsumen dalam membeli daging ayam ras pedaging di pasar tradisional Amuntai (ii) faktor-faktor apa saja yang mempengaruhi perilaku konsumen dalam membeli daging ayam ras pedaging di pasar tradisional Amuntai.

Karakteristik Konsumen

\section{METODE PENELITIAN}

\section{Tempat dan Waktu Penelitian}

Penelitian ini dilaksanakan di pasar tradisional yang ada di Kota Amuntai yaitu Pasar Amuntai. Penentuan lokasi penelitian dilakukan sengaja dengan pertimbangan bahwa pasar Amuntai beroperasi dari pagi sampai sore sehingga responden akan mudah dijumpai di pasar. Penelitian ini dilakukan mulai bulan Maret 2017 sampai selesai. Mulai dari tahap persiapan, pengumpulan data, pembuatan proposal hingga tahap pembuatan laporan.

\section{Jenis dan Sumber Data}

Penelitian dilakukan dengan metode survei dimana sebagian besar data yang digunakan dalam penelitian ini adalah data primer. Data primer diperoleh dari responden melalui wawancara dengan menggunakan kuesioner (daftar pertanyaan) yang telah dipersiapkan dan pengamatan langsung dilapangan. Data sekunder diperoleh dari lembaga terkait yang berhubungan dengan penelitian ini seperti Badan Pusat Statistik dan Dinas Peternakan.

\section{HASIL DAN PEMBAHASAN}

Pengumpulan data dilakukan melalui wawancara dengan menggunakan daftar pertanyaan. Daftar pernyataan yang digunakan dalam penelitian ini adalah mengenai karakteristik konsumen seperti jenis kelamin, usia, pendidikan terakhir, dan pendapatan perbulan. Selain karakteristik konsumen juga mengenai faktor-faktor yang mempengaruhi perilaku konsumen dalam membeli daging ayam ras pedaging seperti faktor budaya $\left(\mathrm{X}_{1}\right)$, faktor sosial $\left(\mathrm{X}_{2}\right)$, faktor pribadi $\left(\mathrm{X}_{3}\right)$, faktor psikologis $\left(\mathrm{X}_{4}\right)$.

Jenis Kelamin

Tabel 1. Karakteristik konsumen berdasarkan jenis kelamin 
Purna Kusumayana \& Selvia Seftiani, Analisis perilaku konsumen...

\begin{tabular}{cccc}
\hline No. & JenisKelamin & Responden (Orang) & Persentase (\%) \\
\hline 1 & Laki-laki & 11 & 14,7 \\
2 & Perempuan & 64 & 85,3 \\
\hline & Jumlah & 75 & 100
\end{tabular}

Sumber: Pengolahan data primer (2017).

Pada Tabel 1 diatas bahwa konsumen

kelamin perempuan 64 orang dengan jenis kelamin yang mendominasi adalah jenis persentase $85,3 \%$.

\section{Usia}

Tabel 2. Karakteristik konsumen berdasarkan usia

\begin{tabular}{cccc}
\hline No. & Usia (Tahun) & Banyaknya (Orang) & Persentase $(\%)$ \\
\hline 1. & $21-30$ & 14 & 18,7 \\
2. & $31-40$ & 19 & 25,3 \\
3. & $41-50$ & 33 & 44,0 \\
4. & $>50$ & 9 & 12,0 \\
\hline & Jumlah & 75 & 100 \\
\hline
\end{tabular}

Sumber: Pengolahan data primer (2017).

Tabel 2 menunjukkan bahwa kelompok usia 41-50 tahun yaitu sebanyak 33 responden yang membeli daging ayam orang dengan persentase $44 \%$. pedaging sebagian besar berada pada

\section{Tingkat Pendidikan}

Tabel 3. Karakteristik konsumen berdasarkan tingkat pendidikan

\begin{tabular}{cccc}
\hline No & Tingkat Pendidikan & Banyaknya (Orang) & Persentase $(\%)$ \\
\hline 1. & SD & 7 & 9,3 \\
2. & SMP & 14 & 18,7 \\
3. & SMA/Sederajat & 34 & 45,3 \\
4. & S1 & 20 & 26,7 \\
\hline & Jumlah & 75 & 100 \\
\hline
\end{tabular}

Sumber: Pengolahan data primer (2017).

Tabel 3 menunjukkan bahwa konsumen yang paling dominan berdasarkan tingkat pendidikan yaitu pendidikan SMA yaitu 34 orang dengan persentase $45,3 \%$.

\section{Pekerjaan}

Tabel 4. Karakteristik Konsumen Berdasarkan Pekerjaan

\begin{tabular}{cccc}
\hline No & Pekerjaan & Banyaknya (Orang) & Persentase $(\%)$ \\
\hline 1. & Pelajar/Mahasiswa & 3 & 4,0 \\
2. & PNS & 8 & 10,7 \\
3. & Swasta & 17 & 22,7
\end{tabular}


4.

Wiraswasta

19

25,3

5.

Ibu Rumah Tangga

Jumlah

28

37,3

75

100

Sumber: Pengolahan data primer (2017).

Tabel 4 menunjukkan bahwa karakteristik konsumen berdasarkan pekerjaan yang dominan yaitu jenis

pekerjaan ibu rumah tangga sebanyak 28 orang dengan persentase $37,3 \%$.

\section{Pendapatan}

Tabel 5. Karakteristik Konsumen Berdasarkan Tingkat Pendapatan

\begin{tabular}{cccc}
\hline No & Pendapatan & Banyaknya (Orang) & Persentase $(\%)$ \\
\hline 1. & $100.000-1.000 .000$ & 23 & 30,7 \\
2. & $1.000 .000-2.000 .000$ & 25 & 33,3 \\
3. & $2.000 .000-3.000 .000$ & 21 & 28,0 \\
4. & $3.000 .000-4.000 .000$ & 5 & 6,7 \\
5. & $>4.000 .000$ & 1 & 1,3 \\
\hline & Jumlah & 75 & 100 \\
\hline
\end{tabular}

Sumber: Pengolahan data primer (2017).

Hasil dari penelitian ini menunjukkan

bahwa tingkat pendapatan perbulan konsumen daging ayam pedaging yang lebih dominan yaitu dengan pendapatan $\mathrm{Rp}$. 1.000.000 - Rp. 2.000.000 sebanyak 25 orang dengan persentase $33,3 \%$

\section{Uji Validitas dan Reliabilitas}

\section{Uji Validitas}

Tabel 6. Hasil Uji Validitas Soal Angket untuk Responden

\begin{tabular}{cccccc}
\hline No & Variabel & Item Soal & $\mathrm{r}_{\text {hitung }}$ & $\mathrm{r}_{\text {tabel }}(5 \%)$ & Keterangan \\
\hline \multirow{2}{*}{ 1. } & \multirow{2}{*}{ Budaya (X1) } & $\mathrm{X}_{1.1}$ & 0,831 & 0,361 & Valid \\
& & $\mathrm{X}_{1.2}$ & 0,868 & 0,361 & Valid \\
\hline \multirow{2}{*}{ 2. } & \multirow{2}{*}{ Sosial (X2) } & $\mathrm{X}_{2.1}$ & 0,846 & 0,361 & Valid \\
& & $\mathrm{X}_{2.2}$ & 0,860 & 0,361 & Valid \\
\hline \multirow{2}{*}{ 3. } & \multirow{2}{*}{ Pribadi (X3) } & $\mathrm{X}_{3.1}$ & 0,792 & 0,361 & Valid \\
& & $\mathrm{X}_{3.2}$ & 0,810 & 0,361 & Valid \\
& & $\mathrm{X}_{3.3}$ & 0,752 & 0,361 & Valid \\
\multirow{2}{*}{ 4. } & \multirow{2}{*}{ Psikologi (X4) } & $\mathrm{X}_{4.1}$ & 0,595 & 0,361 & Valid \\
& & $\mathrm{X}_{4.2}$ & 0,837 & 0,361 & Valid \\
\hline \multirow{2}{*}{ 5. } & \multirow{2}{*}{ PengambilanK } & $\mathrm{X}_{4.3}$ & 0,853 & 0,361 & Valid \\
& \multirow{2}{*}{ eputusan (Y) } & $\mathrm{Y}_{2}$ & 0,631 & 0,361 & Valid \\
& & $\mathrm{Y}_{3}$ & 0,864 & 0,361 & Valid \\
\hline
\end{tabular}

Sumber: Pengolahan data primer (2017).

Tabel 6 di atas menunjukkan bahwa hasil perhitungan validitas soal angket dari 13 butir pernyataan dinyatakan valid. Dari perhitungan nilai $r_{\text {hitung }}>r_{\text {tabel. }}$ 


\section{Uji Reliabilitas}

Tabel 7. Hasil Uji Reliabilitas

\begin{tabular}{cc}
\hline \multicolumn{2}{c}{ Reliability Statistics } \\
\hline Cronbach's Alpha & N of Items \\
\hline, 820 & 13
\end{tabular}

Berdasarkan Tabel 7 di atas, bahwa hasil perhitungan reliabilitas dapat diketahui nilai Cronbach Alpha adalah 0,820. Jika nilai reliabilitas Alpha Cronbach kurang dari 0,6 adalah kurang baik, sedangkan 0,7 dapat diterima dan di atas 0,8 adalah baik (Priyatno, 2014).

\section{Uji Asumsi Klasik}

\section{Uji Normalitas}

Hasil perhitungan SPSS dengan Uji Normalitas

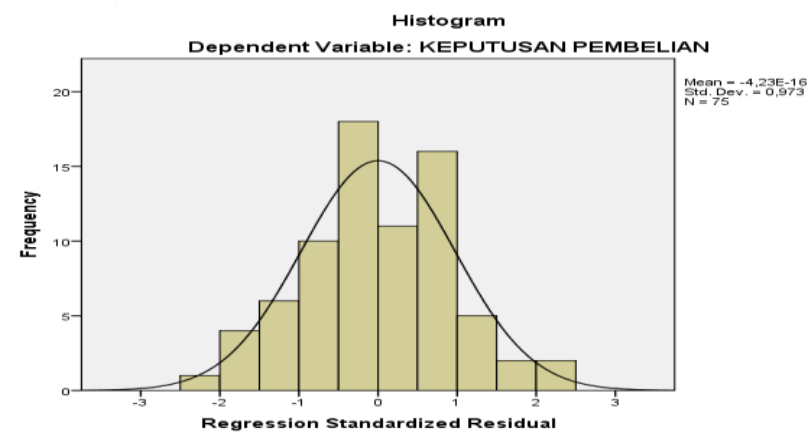

Gambar 1. Hasil Uji Normalitas (Output Histogram)

Berdasarkan Gambar 1 diatas tampilan histogram terlihat bahwa kurva dependent variabel keputusan pembelian (Y) dan regression standardized residual membentuk gambar seperti lonceng. Oleh karena itu berdasarkan uji normalitas, analisis regrasi layak digunakan.

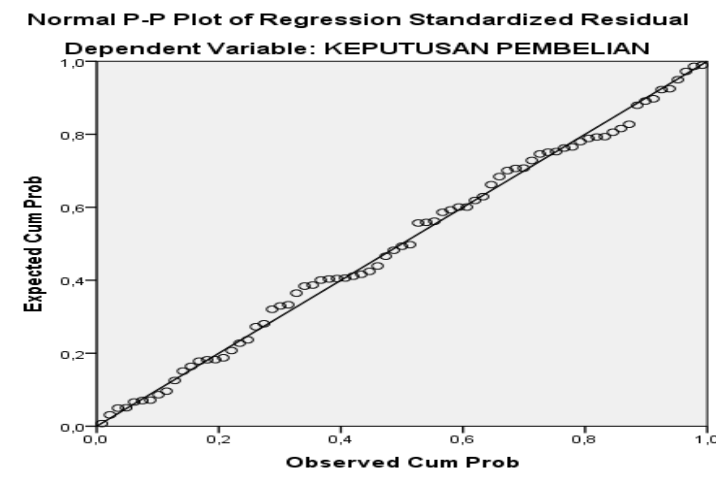

Gambar 2. Hasil Uji Normalitas (Normal P-P Plot Regression Standardized)

Dari tampilan Normal P-P Plot Regression Standardized (Gambar 2) terlihat bahwa titik-titik menyebar disekitar garis diagonal. Berdasarkan uji normalitas, analisis 
regrasi layak digunakan meskipun terdapat sedikit plot yang menyimpang dari garis diagonal.

\section{Uji Multikolinieritas}

Uji multikolinieritas dapat dilakukan dengan melihat nilai Tolerance (TOL) dan
Variance Inflation Factor (VIF) dari masingmasing variabel bebasterhadap variabel terikatnya. Jika nilai VIF tidak lebih dari 10, maka mode dinyatakan tidak terdapat gejala multikolinieritas.

Tabel 8. Uji Multikolinieritas

\begin{tabular}{llcc}
\hline \multirow{2}{*}{ Model } & \multicolumn{2}{c}{ Collinearity Statistics } \\
\cline { 2 - 4 } & & Tolerance & VIF \\
\hline \multirow{nyy}{*}{1} & (Constant) & \multicolumn{2}{c}{1,749} \\
\cline { 2 - 4 } & BUDAYA &, 924 & 1,082 \\
\cline { 2 - 4 } & SOSIAL &, 547 & 1,827 \\
\cline { 2 - 4 } & PRIBADI &, 511 & 1,959 \\
\cline { 2 - 4 } & PSIKOLOGIS & &
\end{tabular}

Sumber: Pengolahan data primer (2017).

Hasil Tabel 8 diketahui bahwa nilai VIF pada variabel budaya $\left(\mathrm{X}_{1}\right) 1,749$, sosial $\left(\mathrm{X}_{2}\right)$ 1,082, pribadi $\left(\mathrm{X}_{3}\right) 1,827$, dan psikologis
$\left(\mathrm{X}_{4}\right)$ 1,959 berjumlah tidak lebih dari 10 , maka dinyatakan tidak terdapat gejala multikolinieritas.

\section{Uji Heteroskedastisitas}

Tabel 9. Uji Heteroskedastisitas

\begin{tabular}{|c|c|c|c|c|c|c|}
\hline \multicolumn{7}{|c|}{ Coefficients $^{\mathrm{a}}$} \\
\hline & \multirow[t]{2}{*}{ Model } & \multicolumn{2}{|c|}{$\begin{array}{l}\text { Unstandardized } \\
\text { Coefficients }\end{array}$} & \multirow{2}{*}{$\begin{array}{c}\begin{array}{c}\text { Standardized } \\
\text { Coefficients }\end{array} \\
\text { Beta }\end{array}$} & \multirow[t]{2}{*}{$\mathrm{t}$} & \multirow[t]{2}{*}{ Sig. } \\
\hline & & $\mathrm{B}$ & Std. Error & & & \\
\hline \multirow{5}{*}{1} & (Constant) & 2,342 &, 641 & & 3,654 & ,000 \\
\hline & BUDAYA &,- 100 & ,093 &,- 163 & $-1,073$ & ,287 \\
\hline & SOSIAL &,- 069 & ,057 &,- 146 & $-1,222$ & ,226 \\
\hline & PRIBADI &,- 064 & ,061 &,- 163 & $-1,050$ & ,297 \\
\hline & PSIKOLOGIS & ,054 & ,049 & , 178 & 1,106 & ,272 \\
\hline
\end{tabular}

a. Dependent Variable: ABRESID

Dari Tabel 9 dapat diketahui bahwa pada model regresi tidak terjadi gejala heteroskedastisitas. Hal ini karena Sig. variabel budaya, soosial, pribadi, dan psikologis lebih besar dari nilai alpa $(0,05)$.

\section{AnalisisRegresi Linier Berganda}

\section{Koefisien Determinasi $\left(\mathbf{R}^{2}\right)$}

Tabel 10. KoefisienDeterminasi $\left(\mathrm{R}^{2}\right)$

\begin{tabular}{ccccc}
\hline Model & R & R Square & Adjusted R Square & Std. Error of the Estimate \\
\hline 1 &, $677^{\mathrm{a}}$ &, 458 &, 427 & 1,226 \\
\hline
\end{tabular}

Sumber: Pengolahan data primer (2017). 
Berdasarkan Tabel 10 bahwa nilai $\mathrm{R}^{2}$ sebesar 0,427 artinya persentase sumbangan pengaruh variabel budaya, sosial, pribadi dan psikologis terhadap keputusan pembelian sebesar $42,7 \%$, sedangkan sisanya sebesar $57,3 \%$ dipengaruhi oleh faktor lain yang tidak dimasukkan dalam model ini.

\section{Model Regresi Linier Berganda}

Tabel 11. Model Regrasi Linier Berganda

\begin{tabular}{|c|c|c|c|c|c|c|}
\hline & \multirow{2}{*}{ Model } & \multicolumn{2}{|c|}{ Unstandardized Coefficients } & \multirow{2}{*}{$\begin{array}{c}\begin{array}{c}\text { Standardized } \\
\text { Coefficients }\end{array} \\
\text { Beta } \\
\end{array}$} & \multirow[t]{2}{*}{$\mathrm{t}$} & \multirow[t]{2}{*}{ Sig. } \\
\hline & & B & Std. Error & & & \\
\hline \multirow[t]{5}{*}{1} & (Constant) & 5,633 & 1,122 & & 5,021 & ,000 \\
\hline & BUDAYA &, 421 &, 163 & ,300 & 2,578 & ,012 \\
\hline & SOSIAL &,- 208 & ,099 &,- 192 & $-2,097$ & ,040 \\
\hline & PRIBADI & ,055 & , 106 & ,061 &, 515 & ,608 \\
\hline & PSIKOLOGIS &, 300 & ,086 & 428 & 3,480 &, 001 \\
\hline
\end{tabular}

Sumber: Pengolahan data primer (2017).

Dari analisis data yang telah dilakukan menggunakan aplikasi Statictical Package for Social Sience (SPSS) 20 muncul persamaan sebagai berikut:

$\mathrm{Y}=5,633+0,421-0,208+0,055+0,300$

Uji F

Tabel 12. Uji F

\begin{tabular}{llccccc}
\hline & Model & Sum of Squares & df & Mean Square & F & Sig. \\
\hline \multirow{2}{*}{1} & Regression & 89,060 & 4 & 22,265 & 14,803 &, $000^{\mathrm{b}}$ \\
\cline { 2 - 7 } & Residual & 105,287 & 70 & 1,504 & & \\
\cline { 2 - 6 } & Total & 194,347 & 74 & & & \\
\hline
\end{tabular}

Sumber: Pengolahan data primer (2017).

Tabel 12 di atas diketahui bahwa nilai bahwa nilai $F_{\text {hitung }} 14,803$ dengan nilai signifikan $F$ sebesar 0,000. Dari nilai $F_{\text {tabel }}$ dengan tingkat kepercayaaan sebesar $95 \%(\alpha$ $=5 \%$ ) nilai df sebesar 4 dan 70 sehingga diketahui nilai $\mathrm{F}_{\text {tabel }}$ sebesar 2,503. Dari hasil tersebut dapat dijelaskan bahwa nilai $F_{\text {hitung }}$ 14,803 lebih besar dari $F_{\text {tabel }} 2,503$ dengan tingkat signifikan 0,000 lebih kecil dari 0,05, sehingga Ho ditolak dan Ha diterima artinya semua variabel independen (X) meliputi budaya, sosial, pribadi, dan

Tabel 17. Uji T psikologis secara simultan berpengaruh terhadap keputusan pembelian.

\section{Uji t}

Uji t adalah uji yang digunakan oleh para ahli ekonometrika untuk menguji tentang koefisien-koefisien regrasi secara individual. Hasil uji t dapa diketahui apakah faktor-faktor yang mempengaruhi seperti budaya, sosial, individu dan psikologis berpengaruh atau tidak terhadap keputusan pembelian 


\begin{tabular}{llcc}
\multicolumn{1}{c}{ Model } & T & Sig. \\
\hline \multirow{3}{*}{1} & (Constant) & 5,021 &, 000 \\
\cline { 2 - 4 } & BUDAYA & 2,578 &, 012 \\
\cline { 2 - 4 } & SOSIAL & $-2,097$ &, 040 \\
\cline { 2 - 4 } & PRIBADI &, 515 &, 608 \\
\cline { 2 - 4 } & PSIKOLOGIS & 3,480 &, 001 \\
\hline
\end{tabular}

Sumber: Pengolahan data primer (2017).

Hasil uji t menyatakan bahwa pada variabel budaya, sosial, dan psikologis nilai $t_{\text {hitung }}$ lebih besar dari $t_{\text {tabel }}(1,66)$ dengan signifikan $<0,05$ artinya berpengaruh terhadap keputusan pembelian, sehingga Ho ditolakdan Ha diterima. Sedangkan variabel pribadi nilai $t_{\text {hitung }}$ lebih kecil dari $t_{\text {tabel }}(1,66)$ dengan signifikan $>0,05$ artinya tidak berpengaruh terhadap keputusan pembelian.

\section{KESIMPULAN}

Karakteristik konsumen pada penelitian ini, sebagian besar adalah konsumen berjenis kelamin perempuan 64 orang dengan persentase $85,3 \%$. Berdasarkan usia yang lebih mendominasi adalah kelompok usia 41-50 tahun 33 orang dengan persentase $44 \%$. Karakteristik konsumen berdasarkan tingkat pendidikan diketahui yang lebih dominan adalah tingkat pendidikan SMA 34 orang dengan persentase 45,3\%. Karakteristik konsumen berdasarkan pekerjaan yang lebih mendominasi adalah pekerjaan ibu rumah tangga 28 dengan persentase $37,3 \%$. Karakteristik konsumen berdasarkan tingkat pendapatan yang lebih dominan yaitu sebesar Rp. $1.000 .000-\mathrm{Rp}$. 2.000.000 sebanyak 25 orang dengan persentase $33,3 \%$.

Hasil analisis regrasi diperoleh nilai koefisien determinasi $\left(\mathrm{R}^{2}\right)$ sebesar 0,427 atau $42,7 \%$ sedangkan $57,3 \%$ dipengaruhi oleh faktor lain yang tidak termasuk dalam model regresi tersebut. Dari hasil pengujian regrasi sebagai berikut:

$\mathrm{Y}=5,633+0,421 \mathrm{X} 1-0,208 \mathrm{X} 2+0,055 \mathrm{X} 3$ $+0,300 \mathrm{X} 4$

Secara simultan variabel independen meliputi budaya, sosial, pribadi, dan psikologis berpengaruh signifikan terhadap keputusan pembelian. Secara parsial faktor budaya, sosial dan psikologis berpengaruh nyata terhadap keputusan pembelian sedangkan faktor pribadi tidak berpengaruh nyata terhadap keputusan pembelian.

\section{DAFTAR PUSTAKA}

Fatah, L. 2007. Dinamika Pembangunan Pertanian dan Pedesaan. Pustaka Banua. Banjarmasin.

Nuroso. 2011. Panen Ayam Pedaging dengan Produksi $2 x$ Lipat. Penebar Swadaya. Jakarta.

Priyatno, D. 2014. SPSS 22 Pengolahan Data Terpraktis. CV. Andi Offset. Jakarta.

Santoso, H. dan Sudaryani, T. 2015. Panduan Praktis Pembesaran Ayam Pedaging. Penebar Swadaya. Jakarta.

Sosilorini, E, T. 2011. Budi Daya 22 Ternak Potensial. Penebar Swadaya. Jakarta. 